\title{
PKM Pendampingan Perancangan Website Pesantren Nurul Abror Ar-Robbaniyyin sebagai Media Penyebaran Informasi Pesantren
}

\author{
Fathur Rizal1, Badrul Rizal Ramdhan², Arief Maulana², \\ Andrian Cahya Dinata ${ }^{4}$, Anugrah Udayaprima Rahmanda ${ }^{5}$, \\ Fadilatur Rohman ${ }^{6}$
}

\author{
Universitas Nurul Jadid, Probolinggo ${ }^{1-6}$ \\ fathurrizal@unuja.ac.id¹ ${ }^{1}$, badrulrizal456@gmail.com², maulanaarief741@gmail.com³ \\ andriancahya233@gmail.com ${ }^{4}$, anugrahudayaprima@gmail.com ${ }^{5}$, \\ fadil.rohman.327@gmail.com6
}

Submission: 01/09/2021 Received: 31/12/2021 Published: 31/12/2021

\section{Keywords:}

Website,

Information,

Pesantren
Abstract. Websites are currently a trend in various government and private agencies. The website is also used by several Islamic boarding schools as a medium for disseminating information on pesantren activities for the community, prospective students and alumni. The Nurul Abror Ar-Robbaniyyin Islamic Boarding School is one of the pesantren located in the Banyuwangi area. The dissemination of information on Islamic boarding schools that has taken place, such as information on returning students, returning students, and other current information about Islamic boarding schools, is using social media such as WhatsApp so that from these problems, pesantren need a website as a medium for disseminating information. The method used to overcome these problems is by observing, interviewing and designing a system that will be built using the waterfall method. The purpose of this service is to provide assistance to the website design process for the Nurul Abror ArRobbaniyyin Islamic Boarding School Banyuwangi. The result of the service that has been carried out is that the Nurul Abror ArRobbaniyyin Islamic Boarding School website has been produced which can be used as a medium for disseminating information on Islamic boarding schools.

Abstrak. Website saat ini menjadi tren di berbagai instansi pemerintah atau pun swasta. Website juga digunakan oleh hbeberapa pesantren sebagai media penyebaran informasi kegiatan pesantren bagi masyarakat, calon santri dan alumni. Pesantren Nurul Abror Ar-Robbaniyyin merupakan salah satu pesantren yang terdapat di wilayah banyuwangi. Penyebaran informasi pesantren yang telah berlangsung hingga seperti informasi pulang santri, kembalian santri, dan informasi-informasi kepesantrenan lainnya saat ini yakni dengan menggunakan media sosial seperti whatsApp sehingga dari permasalahan tersebut pesantren memerlukan website sebagai media penyebaran informasi. Metode yang digunakan untuk mengatasi permasalahan tersebut yakni dengan observasi, wawancara dan merancang 


\begin{abstract}
sistem yang akan dibangun dengan menggunakan metode waterfall. Tujuan dari pengabdian ini yakni melakukan pendampingan terhadap proses perancangan website Pesantren Nurul Abror Ar-Robbaniyyin Banyuwangi. Hasil dari pengabdian yang telah dilaksanakan yakni telah dihasilkan website Pesantren Nurul Abror Ar-Robbaniyyin yang dapat digunakan sebagai media penyebaran informasi pesantren.
\end{abstract}

\title{
1 Pendahuluan
}

Website saat ini menjadi tren di berbagai instansi pemerintah atau pun swasta. Website juga digunakan oleh beberapa pesantren sebagai media penyebaran informasi kegiatan pesantren bagi masyarakat, calon santri dan alumni. Pesantren merupakan tempat dimana seseorang dapat menimba ilmu pendidikan formal ataupun non formal tergantung pendidikan yang telah disediakan oleh pesantren yang bersangkutan dan tentunya pendidikan yang diajarkan didalamnya berasaskan Agama Islam (Setiawan, Sulaksono, \& Wulanningrum, 2019). Selain pendidikan formal dan non formal di pesantren, juga terdapat pula pendidikan tentang ilmu keagamaan seperti kajian/pendalaman mengenai cara membaca kitab kuning, tata cara sholat yang baik, adab terhadap sang pencipta, orang tua, guru maupun sesama manusia (Faid \& Jasri, 2017).

Pesantren Nurul Abror Ar-Robbaniyyin merupakan salah satu pesantren yang terdapat di wilayah banyuwangi. Penyebaran informasi pesantren yang telah berlangsung hingga seperti informasi pulang santri, kembalian santri, dan informasi-informasi kegiatan kepesantrenan lainnya saat ini yakni dengan menggunakan media sosial seperti WhatsApp sehingga dari permasalahan tersebut pesantren memerlukan website sebagai media penyebaran informasi. Metode yang digunakan untuk mengatasi permasalahan tersebut yakni dengan observasi, wawancara dan merancang sistem yang akan dibangun, dalam proses merancang sistem yang akan dibangun menggunakan metode pengembangan sistem waterfall, metode ini digunakan karena memiliki tahapan-tahapan yang sistematis dalam prosesnya (Stefanus \& Andry, 2020) (Hasyim \& Wijaya, 2019). Tujuan dari pengabdian ini yakni melakukan pendampingan dalam proses perancangan website Pesantren Nurul Abror Ar-Robbaniyyin Banyuwangi. Pendampingan dilakukan dari proses pengumpulan data hingga sistem yang dibutuhkan dapat digunakan oleh Pesantren Nurul Abror Ar-Robbaniyyin Banyuwangi. Proses pendampingan dilakukan terhadap beberapa mahasiswa yang telah 
lulus dari perguruan tinggi lulusan prodi informatika dari salah satu universitas yang terdapat di probolinggo. Pendampingan perancangan website ini juga bertujuan agar mahasiswa yang telah lulus dan menetap di Pesantren Nurul Abror Ar-Robbaniyyin tetap dapat mengembangkan ilmu pengetahuan yang telah diperoleh selama kuliah sebelumnya. Oleh sebab itu pendampingan terhadap perangcangan website ini sangat diperlukan untuk memberikan pengetahuan lebih terhadap mahasiswa yang terdapat di Pesantren Nurul Abror Ar-Robbaniyyin sebagai pengalaman baru dalam merancangang serta mengembangkan suatu aplikasi sesuai dengan hasil analisa yang akan telah dilakukan nantinya.

\section{Metode}

Metode atau pendekatan yang digunakan untuk mencapai tujuan dalam pengabdian ini yakni dengan menggunakan pendekatan observasi dan wawancara terhadap perwakilan pesantren dan tim IT Pesantren Nurul Abror Ar-Robbaniyyin. Sebagian tim IT yang terdapat di Pesantren Nurul Abror ArRobbaniyyin merupakan mahasiswa yang telah lulus dari perguruan tinggi. Selain 2 pendekatan tersebut juga menggunakan metode waterfall dalam pengembangan sistem yang akan dibuat, tahapan ini meliputi menganalisa kebutuhan, mendesain sistem yang akan dibangun, Implementasi desain yang telah dibangun terhadap bahasa pemrograman yang digunakan, pengujian sistem dan pemeliharan sistem (Stefanus \& Andry, 2020). Selain beberapa pendekatan yang telah disebutkan, dalam pengabdian ini juga menggunakan studi literatur dari beberapa penelitian atau jurnal sebagai tambahan referensi / landasan dalam mengerjakan sistem atau laporan yang kerjakan. Adapun tahapan dalam pengabdian ini yakni sebagai berikut: 


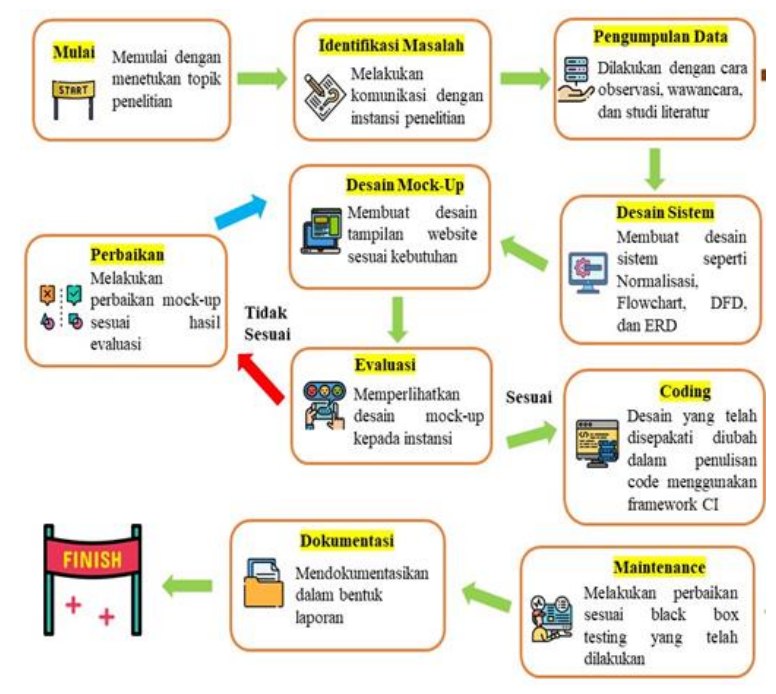

Gambar 1. Diagram Alur Perancangan Sistem

\section{Hasil dan Pembahasan}

Secara umum proses pengabdian kepada masyarakat ini terdapat 4 tahapan yang dilakukan, yakni meliputi:

a. Identifikasi Masalah

Identifikasi masalah dilakukan dengan observasi serta wawancara terhadap perwakilan pesantren dan tim IT Pesantren Nurul Abror ArRobbaniyyin yang menghasilkan beberapa permasalahan yang terdapat di Pesantren Nurul Abror Ar-Robbaniyyin dalam proses penyebaran informasi yang sedang berlangung.

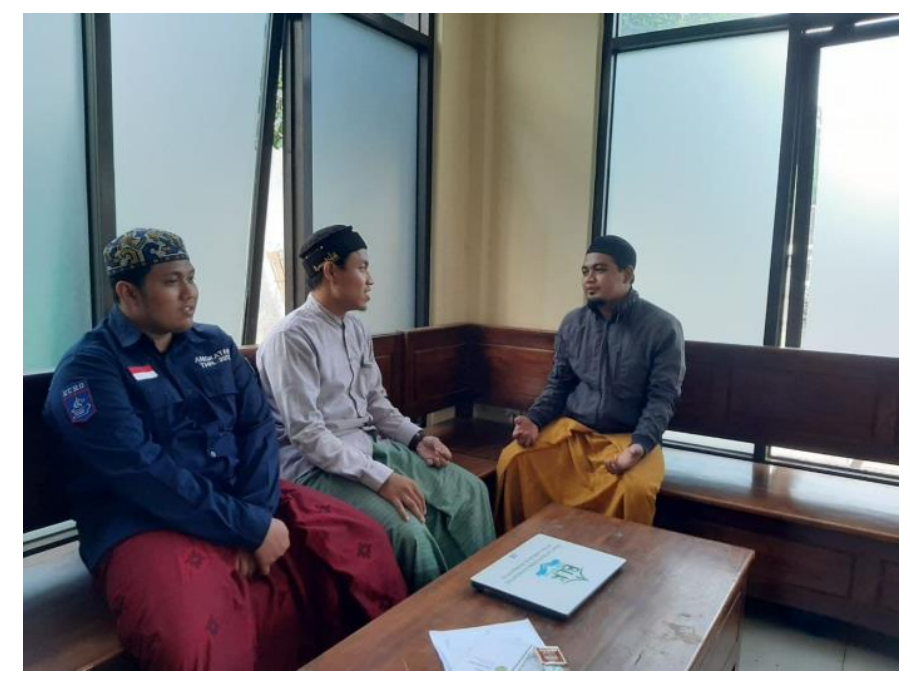

Gambar 2. Proses Observasi dan Wawancara 
b. Pendampingan Desain Sistem

Hasil dari observasi dan wawancara yang telah dilakukan selanjutnya dilakukan analisa terdapat data-data serta kebutuhan yang diperlukan untuk dijadikan sebagai bahan dalam pembuatan desain sistem yang akan dibangun. Desain sistem yang digunakan dalam pengabdian ini menggunakan Data Flow Diagram, dan Entity Relation Diagram. Pendampingan desain sistem dilakukan setiap seminggu sekali.

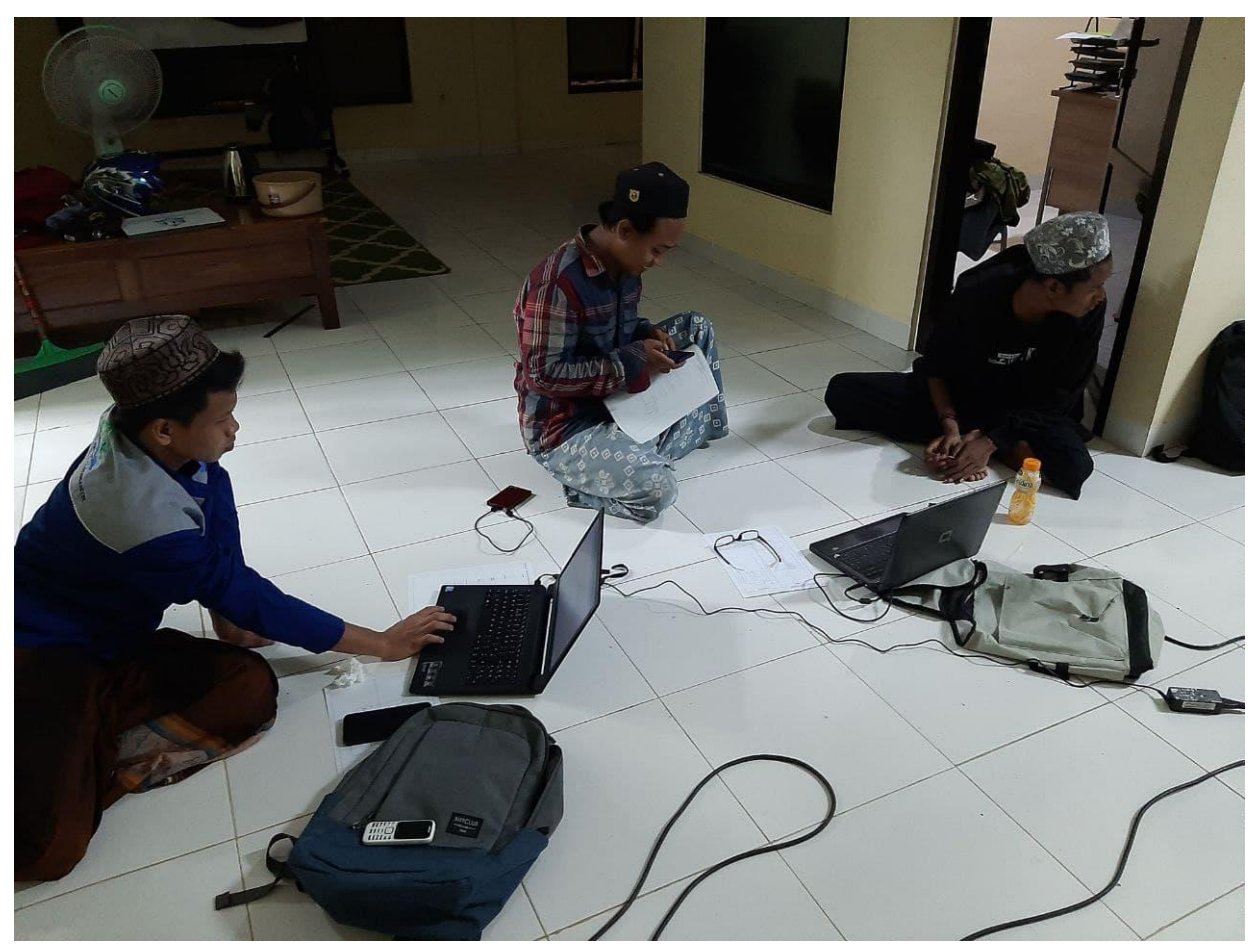

Gambar 3. Proses Pembuatan Desain Sistem

c. Pendampingan Implementasi Sistem

Pendampingan ini dilakukan setelah desain sistem selesai dirancang. Desain sistem yang telah dirancang dijadikan sebagai acuan dalam implementasi terhadap bahasa pemrograman yang digunakan dalam membuat website. Pemrograman yang digunakan yakni menggunakan pemrograman PHP dengan Framework Codelgniter. Adapun hasil implementasi dari pelaksanaan pendampingan ini yakni sebagai berikut: 
1. Desain Halaman Awal

Pada halaman awal ini, pengguna dapat mengetahui informasi berita/kegiatan terbaru yang diunggah oleh tim IT Pesantren Nurul Abror Ar-Robbaniyyin serta terdapat pula pengumuman seputar pesantren yang dapat diakses oleh pengguna.

Selain itu terdapat pula menu navigasi yang terdapat pada sebelah kiri yang meliputi beberapa menu sebagai berikut:

a. Tentang Pesantren NAA

b. Struktur Organisasi

c. Visi dan Misi

d. Madrasah Diniyah

e. Maktab Nubdzatul Bayan

f. Lembaga Pendidikan Formal

Selain menu navigasi yang terdapat di sebelah kiri, juga terdapat beberapa menu pada menubar pada website yang meliput: Beranda, Profil, Galery Foto, Koleksi Video, Pengumuman, Download, Semua Berita, dan menu Hubungi Kami.

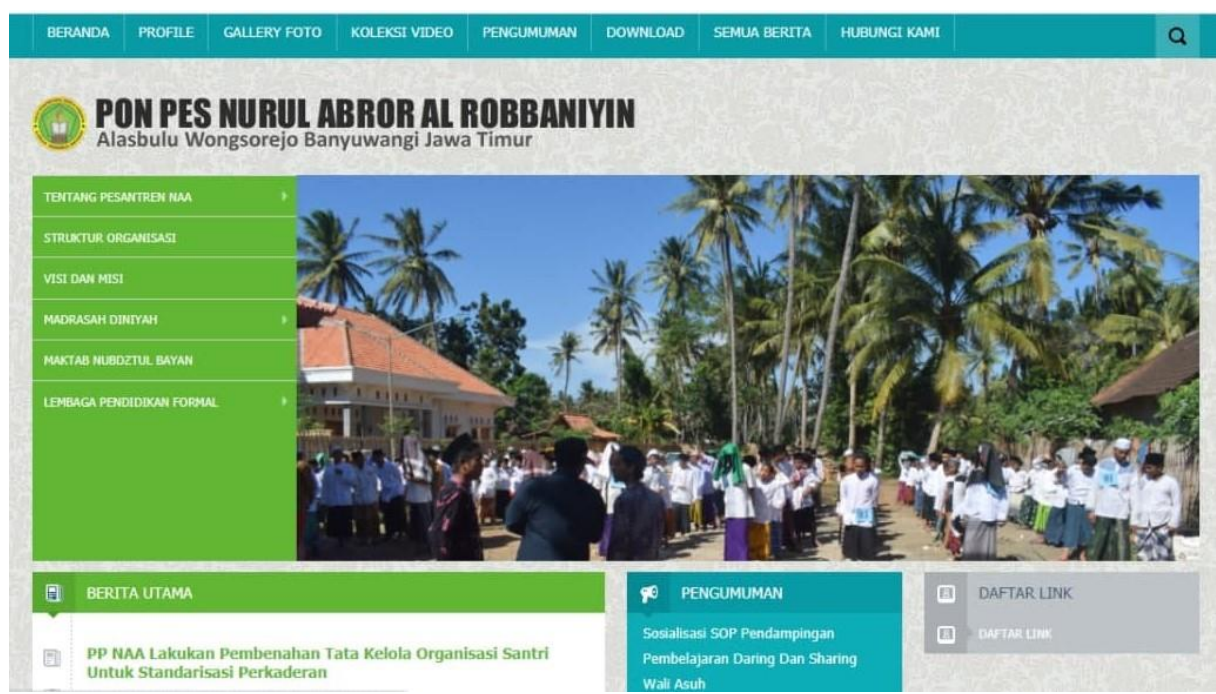

Gambar 4. Halaman Awal

2. Desain Detail Berita / Kegiatan

Pada halaman ini berisi informasi rincian atau detail dari berita atau pengumuman yang terdapat pada menu awal yang dipilih oleh pengguna. Adapun desainnya yakni sebagai berikut: 


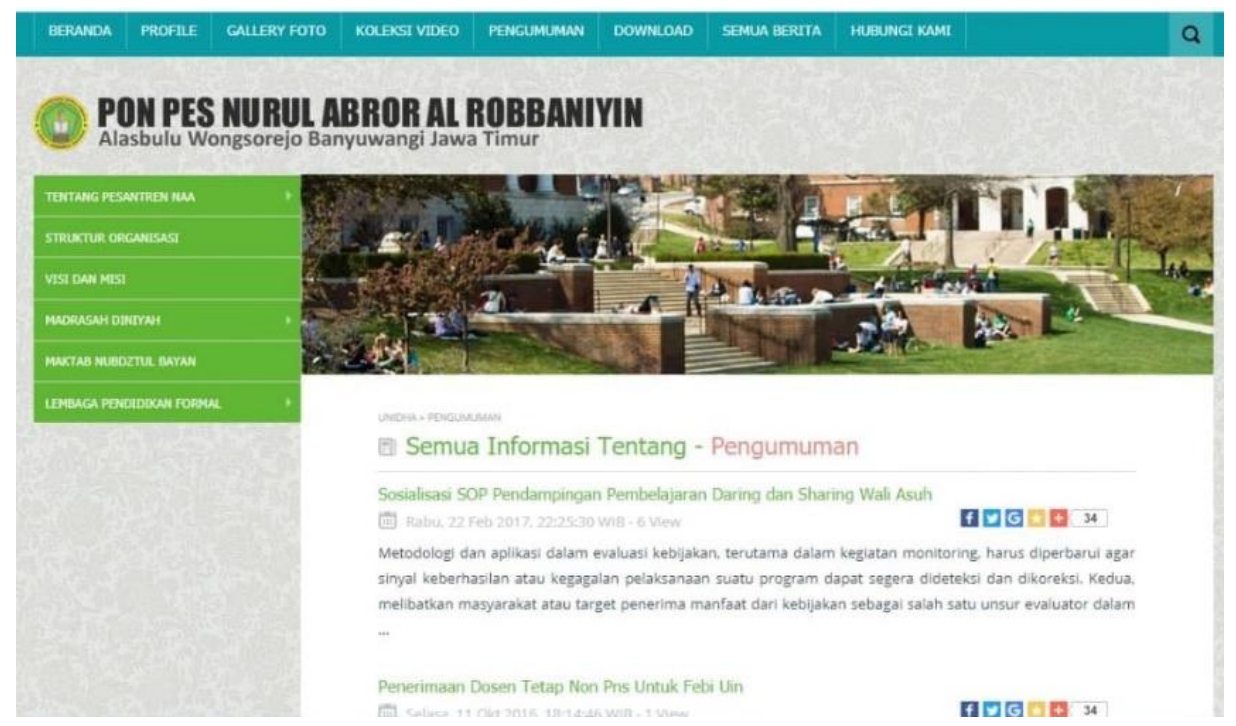

Gambar 5. Halaman Detail Berita / Kegiatan

d. Pengujian Sistem

Setelah proses implementasi desain sistem terhadap bahasa pemrograman dilakukan, tahapan selanjutnya yakni pengujian sistem. Pengujian sistem dilakukan dengan melakukan presentasi oleh tim IT Pesantren Nurul Abror Ar-Robbaniyyin yang dihadiri oleh beberapa pengurus pesantren serta tim multimedia yang nantikan akan mengelola konten-konten informasi yang akan di unggah ke website yang telah buat oleh tim IT. Setelah proses pengujian sistem dilakukan, terdapat beberapa poin penting yang menjadi catatan untuk pengembangan website selanjutnya diataranya yakni:

1. Diperlukan penyesuaian ulang terhadap beberapa menu atau konten yang telah ada

2. Perlu adanya integrasi antara website yang telah dibangun dengan sistem penerimaan santri baru yang telah ada

3. Terdapat beberapa bug yang muncul saat dilakukan pengujian sistem berlangsung

4. Diharapkan terdapat pengembangan sistem yang dapat dijalankan pada smartphone.

Adapun dokumentasi pengujian sistem terhadap perwakilan pengurus pesantren dan tim IT yakni sebagai berikut: 


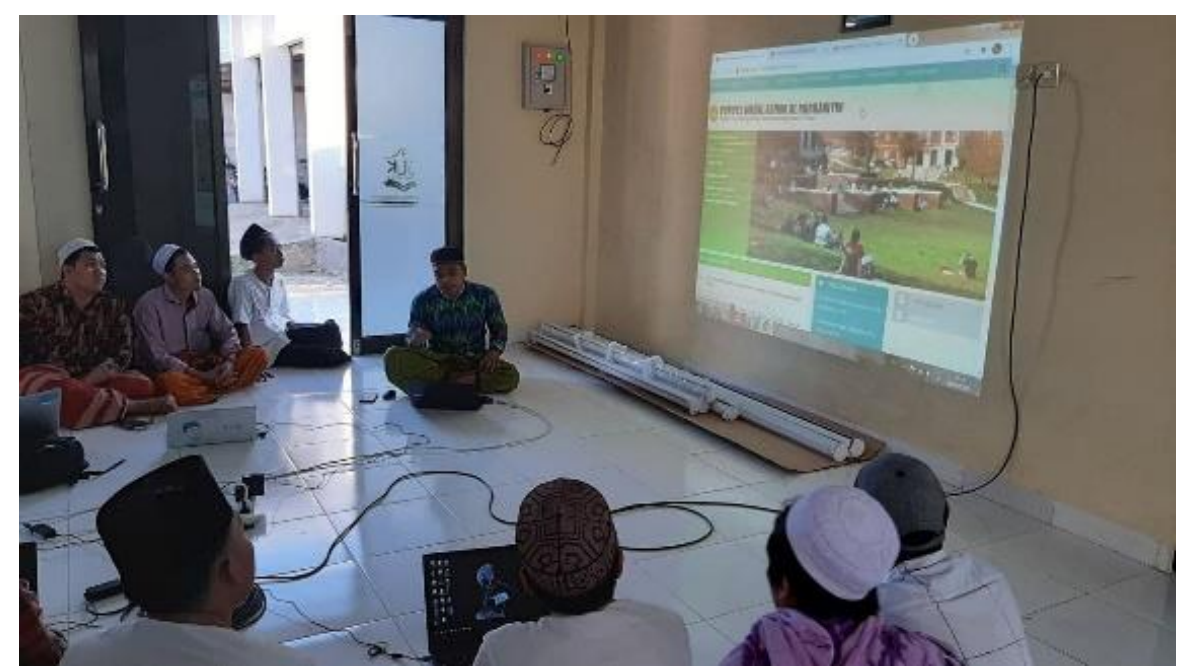

Gambar 6. Presentasi Pengujian Sistem

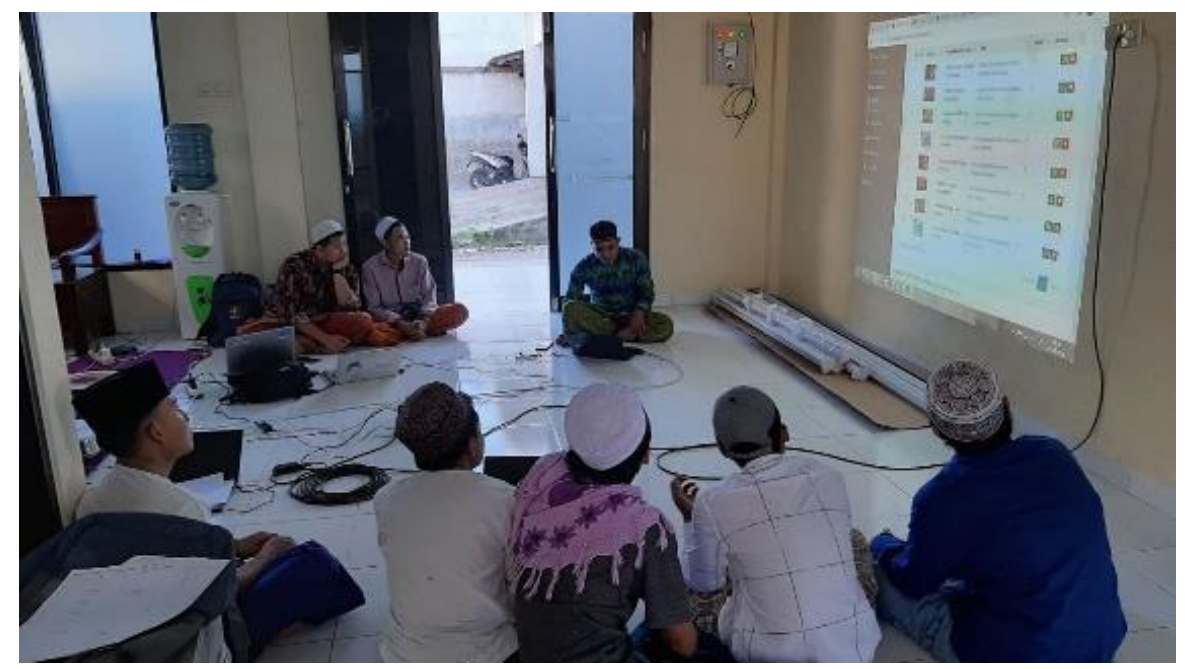

Gambar 7. Presentasi Pengujian Sistem

\section{Kesimpulan}

Hasil dari pendampingan pembuatan website di Pesantren Nurul Abror ArRobbaniyyin dalam program pengabdian masyarakat telah selesai dilakukan dengan beberapa kesimpulan yang diperoleh diantaranya website yang dibangun telah selesai dibuat meskipun terdapat beberapa poin yang harus dilakukan perbaikan serta Tim IT Pesantren Nurul Abror Ar-Robbaniyyin memperoleh pengalaman baru dalam mengembangkan sistem informasi berbasis Tim. Website yang telah dibagun dapat diakses oleh santri, alumni maupun masyarakat. 


\section{Pengakuan}

Ucapan terimakasih kepada pengasuh serta pengurus pondok pesantren Nurul Abror Ar-Robbaniyyin yang telah berkenan menerima serta memberikan fasilitas dalam pelaksanaan Pengabdian kepada Masyarakat Pendampingan pembuatan website pondok pesantren. Serta terimakasih pula terhadap Rektor Universitas Nurul Jadid yang telah memberikan kepercayaan terhadap dosen serta teman-teman mahasiswa dalam pelaksanaan pengabdian kepada masyarakat, kegiatan ini memberikan wawasan lebih bagi mahasiswa selain pembelajaran yang diperoleh dari meja kampus. Tidak lupa pula kepada LP3M Universitas Nurul Jadid yang selalu memberikan dorongan serta bantuan agar terlaksananya pengabdian kepada masyarakat kolaborasi dosen dengan mahasiswa ini. Semoga kegiatan yang telah selesai ini memberikan dampat yang baik bagi pelaksana kegiatan, mahasiswa serta lembaga yang menerima kegiatan ini.

\section{Referensi}

Arifin, Z., \& Malik, K. (2019). Rancang Bangun Aplikasi Monitoring Angsuran Down Payment Berbasis Android Pada Pembelian Property di Perum Griya Permai. Nusantara Journal of Computers and Its Applications, 97-102.

Faid, M., \& Jasri, M. (2017). Sistem Informasi Pengolahan Sampah di Pondok Pesantren Nurul jadid. Seminar Nasional Inovasi Dan Aplikasi Teknologi Di Industri 2017, 1-5.

Fajri, F. N., \& Shudiq, W. J. (2019). Aplikasi "Fire Bus" Sebagai Media Penyampaian Informasi Keberangkatan Bis Secara Realtime Menggunakan Notifikasi Berbasis Android. Nusantara Journal of Computers and Its Applications, 85-91.

Hasyim, F., \& Wijaya, A. (2019). Peningkatan mutu akreditasi perguruan tinggi menggunakan sistem manajemen dokumen elektronik (electronic document management system). Nusantara Journal of Computers and Its Applications, 79-84. 
Setiawan, A. B., Sulaksono, J., \& Wulanningrum, R. (2019). Penerapan Sistem Informasi Berbasis Website di Pondok Pesantren Kota Kediri. Generation Journal, 11-15.

Shudiq, W. J. (2017). Desain Program Sistem Informasi Pengaduan Masyarakat Pada Kecamatan Kedemangan Terintegrasi SMS Gateway. Prosiding SENIATI, 1-6.

Stefanus, M., \& Andry, J. F. (2020). Pengembangan Aplikasi E-Learning Berbasis Web Menggunakan Model Waterfall Pada SMK Strada 2 Jakarta. Jurnal Fasilkom, 1-10.

Sudriyanto, Khairi, A., \& Yaqin, M. A. (2019). Sistem Rancang Bangun One Windows Pendataan Kependudukan di Desa Krampilan Kecamatan Besuk Kabupaten Probolinggo Berbasis Web Bootstrap dan Android App Inventor. Nusantara Journal of Computers and Its Applications, 25-31.

Wijaya, A., Bahtiar, A. S., \& Sholehah, A. F. (2018). Pengembangan Aplikasi Informasi Kehadiran Kegiatan Belajar Mengajar Universitas Nurul Jadid Berbasis Android. Nusantara Journal of Computers and Its Applications, 152-157.

Yaqin, M. A., \& Anis, A. A. (2018). Sistem Advice Planing Online dengan Framework Codeigniter Berbasis Web Bootstrap (Studi Kasus: Kabupaten Probolinggo). Jurnal Informatika:Jurnal Pengembangan IT, 2019-224. 